This item was submitted to Loughborough's Research Repository by the author.

Items in Figshare are protected by copyright, with all rights reserved, unless otherwise indicated.

\title{
Getting service at the constituency office: Analyzing citizens' encounters with their Member of Parliament
}

PLEASE CITE THE PUBLISHED VERSION

https://doi.org/10.1515/text-2018-0014

\section{PUBLISHER}

DE GRUYTER MOUTON

\section{VERSION}

VoR (Version of Record)

\section{PUBLISHER STATEMENT}

This paper was published in the journal TEXT \& TALK and the definitive published version is available at https://doi.org/10.1515/text-2018-0014

\section{LICENCE}

CC BY-NC-ND 4.0

\section{REPOSITORY RECORD}

Hofstetter, Emily, and Elizabeth Stokoe. 2019. "Getting Service at the Constituency Office: Analyzing Citizens' Encounters with Their Member of Parliament”. figshare. https://hdl.handle.net/2134/34772. 


\title{
Emily Hofstetter* and Elizabeth Stokoe
}

\section{Getting service at the constituency office: Analyzing citizens' encounters with their Member of Parliament}

\author{
https://doi.org/10.1515/text-2018-0014
}

\begin{abstract}
In this paper, we present an analysis of how constituents procure services at the constituency office of a Member of Parliament (MP) in the United Kingdom. This paper will investigate how several previously documented interactional practices (e.g. entitlement) combine at the constituency office in a way that secures service. From a corpus of 12.5 hours of interaction, and using conversation analysis, we examine constituents' telephone calls and meetings with constituency office staff and the MP, identifying practices constituents use. First, constituents opened encounters with bids to tell narratives. Second, constituents presented lengthy and detailed descriptions of their difficulties. These descriptions gave space to manage issues of legitimacy and entitlement, while simultaneously recruiting assistance. Third, we examine ways in which constituents display uncertainty about how the institution of the constituency office functions, and what services are available. The paper offers original insights into how constituency services are provided, and how constituency offices give access and support to ordinary citizens, while expanding the conversation analytic literature on institutional service provision.
\end{abstract}

Keywords: request, service encounter, conversation analysis, member of parliament, constituency office, institutional talk

\section{Introduction}

This paper examines the process by which visitors to a constituency office in the United Kingdom, also called an "MP surgery," secure service. Citizens visit to seek assistance with a diverse set of problems, and the Members of Parliament (MPs) and their staff ("caseworkers") attempt to provide what services they can

\footnotetext{
*Corresponding author: Emily Hofstetter, Department of Social Sciences, Loughborough University, LE11 3TU, Loughborough, UK, E-mail: emilychofstetter@gmail.com Elizabeth Stokoe, Department of Social Sciences, Loughborough University, LE11 3TU, Loughborough, UK, E-mail: e.h.stokoe@lboro.ac.uk
} 
to ameliorate the situation. Constituency service is a way for the MP to connect with local residents, to appear (and be) accessible and friendly, and to (hopefully) earn gratitude from citizens that may be repaid at election time (Butler and Collins 2001). Despite the centrality of service provision to the MP's work week, constituency office interactions have only just begun to be examined (Hofstetter 2016; Hofstetter and Stokoe 2015 are the only interactional studies). Despite being the only place where constituents can seek services from the MP face to face, the constituency office has rarely been examined as a site of interaction, let alone for how the participants go about seeking and providing services. This paper reports the first study to examine how constituents do interactional work to procure services in MP surgery meetings.

We use the phrase "procure services" because, at the constituency office, constituents rarely use direct requests, as seen in more streamlined services such as grocery stores or many emergency calls (Drew and Couper-Kuhlen 2014). Constituents launch a detailed description of the circumstances that have preceded their visit to the constituency office. These descriptions are more extended than those reported in previous studies on emergency calls (e.g. Zimmerman 1992) or doctors' offices (e.g. Heritage and Maynard 2006), typically lasting ten minutes or more, and involving an explanation of the history of the problem - as such, we call them "narrative descriptions" (following Halkowski 2006), since they involve detailing the history of how the problem arose and continued.

In this paper, we demonstrate how constituents and office staff open the encounters, how these openings lead into narratives about the constituents' difficulty, and how the narratives manage a display of entitlement, the unreasonableness of their situation, and past attempts at self-help (for previous studies investigating these in other contexts, see, e.g. Curl and Drew 2008; Edwards and Stokoe 2007; Heritage and Clayman 2010; Stokoe and Hepburn 2005). The demonstration of relevance to the constituency office specifically involves indexing traditional "political" roles such as citizens and government. Finally, we will examine evidence for constituents' lack of familiarity with the constituency office, as an extension of Stokoe's (2013) “unknown” institution. This paper contributes both to our understanding of a new institutional environment in the interactional literature, as well as an empirical account of how participants enact what it is to do constituency service.

\subsection{The constituency office}

MPs in the United Kingdom are responsible for creating and modifying policies and laws to govern the country. However, all MPs in the UK claim to meet with 
the constituents they represent, and undertake constituency casework. As part of their role as representatives, MPs maintain contact with the citizens who elected them, and since the medieval times have offered help to individual constituents in need (House of Commons Modernisation Committee 2007). At constituency meetings, constituents may offer criticisms of government policy or opinions about law currently under debate (House of Commons 2013); however, most constituents raise personal difficulties.

There is a large literature debating the usefulness of constituency service (see, e.g. Heitshusen et al. 2005; Vivyan and Wagner 2015), especially as it is not a mandatory part of the MP's role. However, regardless of whether or not the service provision is effective for improving election results, the vast majority of MPs in the UK do engage in constituency service (House of Commons Modernisation Committee 2007), and this aspect of the MP's role takes up the single largest proportion of their time (Korris 2011). MPs in the UK do not charge for services (House of Commons 2013).

Constituents bring a diverse number of issues to the constituency office, both in the corpus in this study and in other studies of constituency offices (e.g. Rawlings 1990a, 1990b). Constituency offices deal with difficulties concerning benefits, housing, immigration, neighbors, employers, local councils and businesses, healthcare, childcare, and a myriad of other issues - sometimes all in the same day. Le Lidec (2009: e122) calls this "the hit parade of difficulties." Although the UK government states "MPs are there to help only with those matters for which Parliament or central government is responsible" (House of Commons 2013), they add in the same document, "[h]owever, constituents often take a problem to their MP because they do not know who else could help them [...] MPs are very generous at giving help and advice" (House of Commons 2013). Such "generosity" is corroborated in research on constituency service (for a review, see Hofstetter 2016) and in opinion pieces where government workers debate the role of the MP (e.g. Gay 2005). MPs often complain about the hours of constituency service (Loat and MacMillan 2014) yet continue to perform services even when it is outside their jurisdiction (Siefken 2014: 10). MPs do not necessarily wish to exclude constituents' concerns as they have a vested interest in helping as many constituents as possible, in order to cultivate gratitude that might be repaid during an election campaign. However, this means that guidelines conflict with practice.

As a result, within the encounters themselves, part of the activity involves sorting out what issues the constituency office may usefully address. Past research has neglected the constituent experience of seeking service in this environment; where constituency research has questioned the constituent, it has been solely on the basis of reported (dis)satisfaction with their representative, with no examination of actual experience or behavior. 


\section{Method and data}

The data were collected at the constituency office of an MP in the UK. The corpus consists of five hours (58 interactions) of audio-recorded telephone calls and seven hours (25 interactions) of video-recorded surgery meetings. Caseworkers (CW in data) took phone calls, and the MP with a caseworker took surgery appointments, case by case. Of these, 28 were first-time visitors (14 by phone), 37 were repeat visitors ( 26 by phone), and 18 were calls to institutions who were not themselves constituents (all by phone), such as the MP helpline or pensions service. Sixty-eight constituents, two caseworkers, and one MP were recorded. All participants gave informed consent to be recorded, and all names in transcripts are pseudonyms. All interactions with constituents (rather than institutions) were included in the collection, which resulted in 65 descriptions of difficulties. Extracts are labelled with a unique code to indicate which are from different surgery meetings, and all constituents are different unless otherwise stated.

The data were analyzed using conversation analysis (CA). For an extended discussion of CA and its use, see Sidnell (2013). The data were transcribed using Jefferson's (2004) notation (see the Appendix) and examined to reveal how the meetings unfolded for potential overall "phases" such as requesting or stating a reason for visiting. The ubiquity of offers (see Hofstetter and Stokoe 2015) and lack of directly requesting turns led to an examination of how the sequences secured service, which is presented below.

\section{Strategies for securing service}

In this section, we analyze how constituents present their problem. We do this by showing how constituents do work to secure service during the constituency office encounters, starting with the encounter opening with a bid to tell a longer turn (Section 3.1), through the narrative-like descriptions employed to detail troubles (Section 3.2), and evidence for unfamiliarity with the institution (Section 3.3).

\subsection{Openings and non-conforming answers to "how can i help"}

We will first focus on the openings of encounters, demonstrating how participants begin the process of service from the first moments of the call or visit. We will show that constituents do not open with direct requests for service, but tend to launch into a lengthy narrative that makes service relevant. 
Constituency office staff typically initiate all encounters with the phrase, "How can I/we help?". In many service encounters, a request is due early in the encounter, often directly after "How can I help?" or other hearably standard openings (e.g. "Dr Jones' office” or "Midcity emergency", see Sikveland et al. 2016; Zimmerman 1992; respectively). For example, in emergency calls, one might respond "I need the paramedics please", (Zimmerman 1992: 436) or in calls to a flight sales center, "Yes I'd like to make a reservation for a flight ticket please?” (Lee 2009: 1252). When making these initial responses, participants can design their turns to convey the degree of entitlement they have to make the request, and the degree of contingency required to fulfill it (Curl and Drew 2008).

In contrast, constituency office openings lack a hearable request following the institutional opening or "how can I help" invitation, as seen in the face-toface surgery meeting below. The transcript begins with the "official" opening at "how can we help" (line 1), after the constituents have entered the office space and sat down.

\section{(1) (MP01.Surgery-1KO_01)}

1 MP: So. (0.2) How can we:: ${ }^{\circ}$ how can we help. ${ }^{\circ}$

$2 \quad(0.9)$

3 C: Well, (0.9) I had ay: (0.4) assessment'hh. (0.9)

4 Eighteen months ago,

5 MP: Right,

$6 \quad(0.9)$

7 C: Which stated that I was (0.3) fit an' capable, (0.6)

8 For work. =

9 MP: = Right,

C does not respond with a request or an answer to the MP's opening. Instead, C's "Well" (line 3) indicates his orientation to the non-action conforming nature of his turn (Schegloff and Lerner 2009). A "non-conforming” turn is one that does not follow the structure projected by the prior turn (Raymond 2003), and in these cases, it involves turns that do not answer the "how can I help" question. C then projects a narrative is upcoming by referencing a past event, which necessarily raises the question of why such an event is relevant to the interaction now. The turn projects that $\mathrm{C}$ will explain the relevance of the past event, but requires the talking space to do so. The MP aligns with this projection; in saying "Right," (line 5), he indicates his understanding that $\mathrm{C}$ has begun to do a telling, passes on taking a substantial turn himself, and grants talking space to $\mathrm{C}$. This opening structure is common in the corpus: 
(2) (MP01.Surgery-1KZ3_02)

1 MP: So. = How can I- (0.2) How can we h [elp.

2 C: [Well, $>$ I've

3 called on behalf < of me daugh:ter:

4 MP: Yes.

5 C: Now she's forty one.

6 MP: Okay,

7 C: Now, (0.3) Uh I know we can't really do anything at-

8 now. But $\mathrm{k}(\mathrm{h}) \mathrm{hh}($.$) over tens years ago we were,$

(3) (MP01.Surgery-2BZ2_01)

1 MP: How can- (0.6) How can we help,

2 C: $\uparrow$ Basically, uhm:, $<$ I.'ve now been put on the, $>$ as my

3 doctor says, scrap heap, because of my illnesses,

4 .hh[h Uh:m:

5 MP: $\quad[$ Right,

6 C: $\quad$. hhh $<$ I've had $>$ pre-eclampsia, (.) eighteen $=$ nineteen

7 years ago

Extracts (2) and (3) likewise show non-conforming responses: "Well, > I've called on behalf < of me daugh:ter:" (lines 2 and 3) and "个Basically, uhm:, < I:'ve now been put on the, > as my doctor says, scrap heap" (lines 2 and 3), including orientations to the non-conforming nature ("Well" and “个Basically,”). These turns open up the opportunity to start a narrative, while also displaying that their trouble cannot be briefly stated (similar to Heritage and Robinson 2006). The MP responds by giving continuers and thus "go-aheads" for the constituents to tell their narratives (lines 4 and 6, and line 5, respectively). Each of these encounters continue with similar opening moves: from "How can I help", through a narrative projection, followed by staff passing on a turn, and the constituent continuing the narrative (for the narrative, see Section 3.2 below). Some constituents have visited the MP's office before (e.g. community organizers, those with an ongoing case), and they open differently:

(4) (MP01.Phone-2CG_05)

1 CW: Jacob Moore's office, $\uparrow$ Gail speaking, how can I

$2 \quad \downarrow$ help you.

3 C: $\quad \mathrm{Oh}=$ hi Gail can I $\uparrow$ talk to you for a minute,

4 CW: Oh hi::, yes, 
(5) (MP01.Phone-1LB_06)

((phone passed to different caseworker))

1 CW: Hi there:

2 C: Hi:, you'al'right? =

$3 \mathrm{CW}$ : = Yes not too bad.= n'you,

4 C: Yes fine thank you, .hh um: s'j's wondering if you'd

5 heard anything cause you'd- uh::m I think you spoke to

6 my husband you said (.) hopefully to be able to tell

7 'im something within ten da:ys,

(6) (MP01.Surgery-2AO_01)

1 CW: Michael Johnson's office $\uparrow \underline{A: n n}$ speaking how can I

2 help you,

3 (0.3)

4 C: uh Good morning Ann: this is Herbert speaking,

$5 \quad(0.6)$

6 CW: Hello.

$7 \quad(0.4)$

8 C: Hello:. I live in'uh:: in Felton,

$9 \quad(0.6)$

10 CW: Yea

11 C: Uhm::: An:d (.) abou- about two years ago maybe two

12 and a half years ago, .hhh I:: slipped and fell,

In Extracts (4)-(6), the constituents all demonstrate familiarity with the office and how it runs. Extract (4) shows the participants switching from an institutional opening to a greeting with someone they know via the "oh hi" turns (lines 3 and 4). Extract (5), after greeting and identification, the constituent asks about their ongoing case for an update. These extracts show constituents demonstrating fluency in what is requestable from the office. Extract (6) shows a deviant case: the constituent designs his opening as though his name will be recognized, but CW does not clearly indicate she recognizes him. The constituent then continues in the same manner as a first-time call, starting a narrative. Extract (6) demonstrates that the caseworker must ratify a constituent's fluency - it is not a knowledge state but a socially constructed demonstration of understanding.

The constituent turns in Extracts (4) and (5) are much closer to "requests," turns that directly ask for service, and requests displaying some entitlement as well. As per Curl and Drew (2008), entitlement is how a participant designs a 
turn to display expectation of having the request fulfilled, and contingency is how the turn is designed to orient to potential circumstances that may be involved in fulfilling the request, such as effort or ability. Extract (4) shows the constituent directly asking to speak to a caseworker, with a comparatively high entitlement design; however, the service she is requesting is low contingency ("just" talking). Extract (5) shows orientation to contingency with the constituent saying she's "j's wondering” (line 4) and mentioning the timeframe as part of her entitlement to ask. In Extracts (1)-(3) (and [7]-[9] below), constituents do not display enough entitlement to even make a request.

First turns in service encounters that bid for extended turn space are not unique to the constituency office. This is achieved by referencing their own positioning to the event, and leading those details into a description of a possible trouble and emergency-worthy event (Zimmerman 1992: 438-439). This style of opening has also been seen in helplines ("I'm concerned about...”, Potter and Hepburn 2003: 204), service centers (“I’ve installed Office Ninety Seven and...”, Baker et al. 2001: 51), and in calls to mediation centers ("I've been talking to somebody else, I don't think there's anything that you might be able t-”, Stokoe 2013: 292). These turns do not request assistance, but initiate a narrative that builds towards the reason-for-calling. The request, or service procurement, remains implicit.

The opening style seen above with first-time constituents accomplishes several tasks. First, it provides space for a narrative while resisting any implication that their difficulty is simple or easily explained. Much as "well" (Schegloff and Lerner 2009) projects that the answer is not straightforward, the turn styles above (many of which incorporate the "well" token, Extracts [1] and [2]) do the same. This also provides space to manage the identity of the problem holder - it may not be the caller but instead their daughter, for instance, who is in need of help. Second, Stokoe (2013: 293) found that the narrative style of opening conveys that the institution and its remit are unknown, which prompts explanations of services (see Section 3.4 below). Third, Heritage and Clayman note that the narrative style is "particularly useful for ambiguous troubles whose actionability may be subject to doubt” (Heritage and Clayman 2010: 76). Fourth, the opening avoids requesting a service that may not be available or possible, which means that both constituents and staff can avoid a dispreferred turn structure (Pomerantz 1984). Finally, the narrative description as a practice provides structural opportunities for the MP or caseworker to make an offer. By leaving the choice of when to make an offer, and what offer to make, constituents can avoid prematurely narrowing the field of what services might be given. All of these components progress the interaction into the narrative of the constituents' difficulty, which we describe below. 


\subsection{Narrative descriptions}

In the previous section, we outlined how openings at the constituency office are brought off; we showed differences between repeat and new visitors, and showed that newly visiting constituents in particular resist giving a direct answer to "how can I help"; instead they project a narrative about their problem. In this section, we describe the way constituent narratives are accomplished, showing that they orient to service-related issues that have been previously documented, such as legitimacy of the problem and prior self-help. We then discuss how constituents manage relevancy (Section 3.2.1).

In making a request for service, clients orient to several issues that have been well-studied in conversation analysis: the relevance of the request for the institution's remit, the ability of the institution to solve it, and the legitimacy of the request. For instance, clients need to demonstrate that their problem is "doctorable” (Heritage and Robinson 2006), "mediate-able” (Edwards and Stokoe 2007), or "policeable” (Whalen and Zimmerman 1990). These interactional achievements can occur together; demonstrating the severity (and thus legitimacy) of an issue can also demonstrate the relevance of seeking expert help, or the reasonableness of the client who has put up with the problem until now. Constituents' use of lengthy narrative descriptions addresses these contingencies.

The narrative descriptions also allow structural space for the constituency office staff to intervene with offers. In other words, the narratives achieve "recruitment" (Kendrick and Drew 2016). Recruitment is the achievement of assistance or aid via the demonstration of some trouble. The demonstration of need has been shown in several studies to be sufficient to make giving assistance relevant (e.g. Gill et al. 2001; Sterie 2015), and it is the same with constituency office encounters. Drew has also found that "by just reporting some activities/circumstances, speakers can get recipients to make proposals for arrangements arising from what is reported" (Drew 1984: 131); giving narrative descriptions promotes the relevance of handling the upshot of those details. Narrative descriptions involve lengthy, incrementally built troubles tellings, often lasting over ten minutes. Due to space restrictions, some details of the telling must be omitted.

The following example shows an expanded Extract (1), in which a constituent has had his benefits cancelled, despite being unable to work due to multiple sclerosis. He is contacting the MP because he cannot get a date fixed for his appeal of the cancellation.

(7) (MP01.Surgery-1KO_01) (expanded from Ext. [1], same constituent as Ext. [1])

1 MP: $\quad$ So. (0.2) How can we:: ${ }^{\circ}$ how can we help. ${ }^{\circ}$

2

$(0.9)$ 


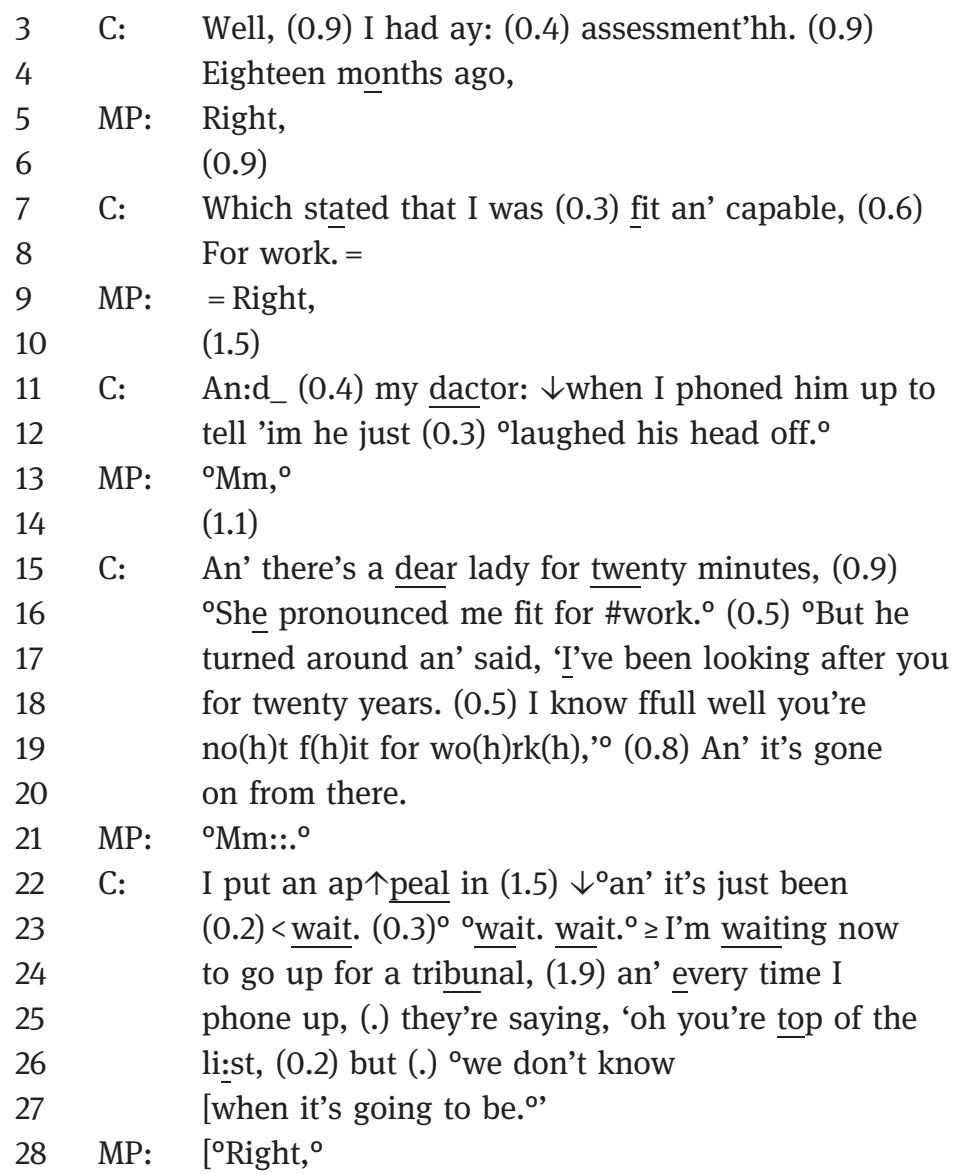

C designs this telling to show how unreasonable his situation is. He has been assessed as "fit an' capable, (0.6) for work" (lines 7 and 8). However, the lady who assessed him took a mere "twenty minutes" (line 15) to do the assessment, whereas his doctor, who has been looking after him for "twenty years." (line 18) finds such an assessment literally laughable (line 12). $\mathrm{C}$ also demonstrates that his inability to get an appeal date fixed is unreasonable; the wait time is characterized with a three-part, repeating list ("< wait. (0.3) ${ }^{\circ 0}$ wait. wait. ${ }^{\circ}>$ ", line 23), and an extreme case formulation ("every time”, line 24, see Pomerantz 1986) wherein the appeals tribunal consistently fails to provide him with a date (lines 24-27). C also shows how he has helped himself (Edwards and Stokoe 2007), in that he has seen his doctor, put an appeal in, and is calling the appeals tribunal repeatedly. The MP gives continuers, encouraging the telling to progress 
(lines 5, 9, 13, 21, 28). Extract (8) further demonstrates the same features. In this extract, the constituent has been trying to get into council-supported housing.

(8) (MP01.Phone-1KZ_01)

1 CW: How can I help you.

$2 \quad(0.4)$

3 C: Well, (.) I live on a boa:t,

4 CW: Yea.

$5 \quad(0.6)$

6 C: And I've just been diagnosed with kidney failyure, =

$7 \quad \mathrm{CW}: \quad=\mathrm{Oh}: \downarrow$ dear,

$8 \quad(0.5)$

9 C: $\quad$ And I am having (0.3) dialysis regular three times a

10 wee:k,

11 CW: Ye:a.

$12 \quad(0.7)$

13 C: $\quad$ Erm, (0.7) Then I had a $<$ heart attac $[\mathrm{k},>$

14 CW: [个Oh:: $\downarrow$ dear,

$15 \quad(0.3)$

16 C: Eheh (0.4) An' (0.2) on the eighteenth of December

17 I've got to go in hospital an' ha:ve (.) a triple

18 heart bypass,

19 CW: .hh Ri:ght?

$20 \quad(0.7)$

21 C: Uhm, (0.5) Living on a boat has been (.) quite

22 difficult for me at the moment,

23 CW: eYeshh.

((9 lines omitted, C explains attempts to get a house))

33 C: Now I've been on [their list for,

34 CW: [ $\quad\left[{ }^{\circ}\right.$ Khkhmmhhh ((clearing throat))

35 C: It'll be two years after Christmas, (0.2) An' I- I

36 just can't seem to $\uparrow$ get $\downarrow$ anywhere with [them,

37 CW: [.hhh Have

38 you been bidding,

$39 \quad(0.8)$

40 C: Y- Well, (.) When anything's on that \# I-\# I want,

C tells a list of troubles (lines 6, 9, 10,13, 16-18), the upshot of which is that she wants to move out of her boat and into a house (lines 21 and 22). C also mentions 
that her health problems are receiving treatment ("diagnosed", line 6, "having (0.3) dialysis regular three times a wee:k" lines 9 and 10, "go in hospital", line 17), and are therefore officially recognized. She has waited for two years before seeking further help (line 35), which CW later confirms is a surprisingly long time. All these suggest that $C$ has a legitimate problem and some entitlement to help. Saying “I just can't seem to 个get $\downarrow$ anywhere with them” (line 36) could suggest that C has tried to speak with the council ("them"), but it is unclear; it could also suggest she is endlessly waiting. CW then checks whether $\mathrm{C}$ has been engaging in the required "bidding" process (a system of requesting council properties and being evaluated by need). CW's check clears the ambiguity about C's efforts at self-help so far, suggesting that CW's first recourse is to check whether $\mathrm{C}$ is engaging in the necessary processes on her own before providing assistance.

Across the corpus, the constituents describe their problems in ways that portray their problem as unreasonable and as something they have previously attempted to solve. Where there is ambiguity about whether these conditions are fulfilled, the staff may check on what constituents have done to help themselves, further emphasizing the importance of this orientation. In the above extracts, constituents demonstrate general relevance of aid, by mentioning their difficulty; however, the specific role of the constituency office vis-à-vis that difficulty is not explicit. In the next section, we examine how constituents can draw relevance to the specific institution of the constituency office.

\subsubsection{Institutional relevance}

Although constituents demonstrate the general relevance of aid from someone, the relevance of the MP's aid specifically is less common. In this section, we show some instances where constituents orient to the specific role of the constituency office. Such mentions do not occur in every interaction, nor always in a sequence concerning the reason for visiting. Explicit political references to political parties, Parliament, or the government, are rare. Only three interactions involve explicit discussion of political policy. However, shorter references to citizenship, legislation, or federal roles (versus local council roles), do appear (eight surgery interactions, six calls), and appear in the context of indexing a relevant reason for visiting.

In the following extract, the constituents (who are partners) have neighbors who are selling drugs, and the police are not taking action. 
(9) (MP01.Surgery-2BG_03)

1 C1: [They've started up again [haven't theyhh

2 C2: [They've started again,

3 an', we- you know ih- in- $>$ in this day an' age $<$ we-

4 we're- we're (0.6) law abiding ci [tizen]s,

5 MP: [Yea, ]

6 C2: We pay our taxes, We always have done,

7 MP: Yea,

8 C2: An':: we feel it's wrong, that er:m: that it's

9 al [lowed to continue,

10 C1: [Been honest, really, 'aven't [we,

11 C2: [Yeah.

12 [We're- we're- we-] [We're honest as the] day is long.

13 C1: [Tuh this, ] [you know, t- ]

14 MP: [Yea. ]

15 C2: [We al]ways have been. We always- always will be,

16 (0.5) An' that's- that's one issue that we have,

17 MP: Ok[ay,

18 C2: [An' we thought .hh you know, (0.6) Well,

$19{ }^{\circ}$ we'll talk to the emm pee ((MP)). ${ }^{\circ}$

20 MP: [That's fine.]

21 C2: [We'll do it.] = We'll do it (0.2) properly,

After explaining the situation (mostly not shown), C2 says he and C1 are "law abiding citizens" (line 4). C1 and C2 collaboratively state evidence to support this category, of always paying taxes and being honest (lines 6, 10-15). C2 links the evidence and "good citizen" category, using "an'” ("and", lines 8, 20), with feeling that the situation is wrong, as well as with their idea to speak to their MP. In referencing their citizenship, they draw on the relevance of the constituency itself, indexing their relationship with the staff as constituents, as members of the geographical zone in which the MP is elected and that the MP represents. The category of (good) citizen draws on the connection to other citizens and public services (e.g. police), and the expectation of them acting reasonably. The turn design highlights their categorical connection to the MP and constituency while also highlighting the unreasonableness of how their neighbors have failed to uphold the same category-bound attributes (goodness, honesty). In this way, relevancy and unreasonableness are accomplished together. 
In the next extracts, the constituents each mention the government role of the MP as a reason for contacting the office.

(10) (MP01.Surgery-2BZ2_01) (same constituent/meeting as Ext. [3]) ((PIP and ESA are types of state benefits))

1 C: $\quad$ Citizen's Advice at Felton, (.) m- $<$ I must say,

$2<\mathrm{h}$ - are absolutely fantastic. $>$

3 MP: ${ }^{\circ} \mathrm{Good} .^{\circ}$

4 C: $\quad$.tch An' (0.7) The praise I can give them, They've

5 helped me so: much with my ee ess ay $((\mathrm{ESA})),=$ my- $($.

6 pee eye pee ((PIP)) [I've applied for:,]

7 MP: $\quad$ [M'm:. Mm:. ]

$8 \quad$ C: $\quad$ But this one they've said, (.) Val your: case is so

9 unique, (.) now:, (0.3) we can't do anything.

10 C: You know because, .hh (.) this is legislation [:,

11 MP:

$\left[{ }^{\circ} \mathrm{Mm}^{\circ}\right.$

(11) (MP01.Surgery-2BG_02)

1 C: An' then (.) what trigg'ed it off, an' there's reason why I came, > an'- an'< made appointment with you, .hh I had spoken to Ca:rla > an' obviously she's been very informative with me, $<$.hh But it's wher:e they said $(0.3)<$ central government policy. > $(0.3)$

7 MP: Mm:,

8 C: $\quad \uparrow O k a y$. You $>$ wanna mention central government, $<$ (.)

$9 \quad$ I'll go see my Em [ ${ }^{\circ} \mathrm{Pee}^{\bar{\circ}}((\mathrm{MP}))$.

10 MP: [Yeah: y[eah:.

11 C: [Cause $\uparrow$ you're- $\uparrow$ you

12 brought the Em Pee into this, (.) $>$ you know $<$ I haven't.

13 I tried to do it through (.) discussion.

(12) (MP01.Phone-1KK_03)

1 C: $\quad$ so hh I'm just wonderin' if there's anythin': that

$2>$ could be done = I've obviously $<$ as they've sort of caused

3 this problem in the first place (0.7) uhm: whether (0.9)

4 anything can be done whether sort of p'litic involvement

5 could- could do anything,

6 CW: .HH Right well let's give it a try, 
In Extract (10), the constituent explains that she has been referred to the office from another social service because her issue revolves around legislation (line 10), which is a government domain. In Extract (11), the constituent claims that the local councillor with whom he is arguing pointed to "<central government policy. >" (line 5) as the rationale for her behavior. The constituent responded to this claim by saying that if she wishes to make central government relevant, "I'll go see my Em Pee" (line 9). Lastly, in Extract (12), the constituent asks "whether sort of p'litic involvement could- could do anything" (lines 4 and 5) to help his problem, which labels the constituency office as the said politic involvement. Each of these draws on a connection to the government category that is tied to the constituency office, and each is used as part of explaining the reason for contacting the office.

Constituents make their case specifically relevant to the constituency and Member of Parliament by referencing political categories such as citizen or government. These categories index the relationship between the MP and the citizen, providing for the relevancy in contacting the former. However, while such relevance appears to be a useful resource, it is not necessary, given that many cases do not draw such a connection.

In the final section, we present the evidence for constituents' lack of familiarity with the constituency office.

\section{3 "unknown" elements of the institution}

The constituency office is comparatively enigmatic as an institution. Three forms of unsystematic feedback suggested it is worth examining the "unknown" nature of the constituency office in the data itself. First, informal interviews with constituents waiting to be seen showed constituent uncertainty about whether the MP could help at all, and if so, in what way. Second, in data sessions with this material, other analysts often try to pin down what it is that the MP "does" as part of understanding the context; as discussed in the introduction, the MPs themselves have difficulty formulating this. Third, many more people have experience of visiting the doctor (indeed, there is evidence that children are socialized into how to be a patient, e.g. Stivers 2011) than visiting their MP. Likewise, the acts of purchasing or requesting repair (Baker et al. 2001; Lee 2009), or of calling emergency services (Zimmerman 1992) are more frequent and more familiar than speaking to an MP. Together, these suggested examining if and how orientations to this unknown nature appeared in the data: to what extent do participants orient to figuring out what the MP "does" as an institution, and how their request fits with that institution? Such a question echoes 
Stokoe's (2013) "unknown" institution barrier in mediation calls, wherein mediators selling a service had to introduce or explain what their service could provide before, or as part of, offering the service itself. We will show that constituents show some lack of familiarity with how the office works and what services are available, but that the focus remains on describing a problem and finding some actionable service.

First, as seen in Extracts (1)-(6) above (Section 3.1), there is a marked difference in openings between constituents who are familiar with the office, and those who are not. New visitors open with a non-conforming turn and a narrative. Familiar visitors explain their request at the outset. Repeat constituents demonstrate their competence in the office workings by showing familiarity with the caseworkers and by making more entitled requests.

There is more evidence than the lack of familiar tokens suggesting some difficulty for at least some new constituents. Many give explicit indications they are uncertain of what to do or to whom to speak. For example:

(13) (MP01.Phone-1KK_03) (same constituent as Ext. [12])

1 CW: Michael Johnson's office $\uparrow \underline{A: n n}$ speaking how can

2 I help you.

3 C: $\quad{ }^{\circ}$ Hello there. ${ }^{\circ}$ uh: I've been tryin' to send an email

((6 lines, consent to record))

10 CW: Thank you. .hhH Right. So are you trying to

11 email Michael or: me or

12 C: Uh well $\underline{y}$ - uh-uh I don't really know $>$ to be honest <

13 I'm- I'm it's > a bit of < uh: (0.5) bit of a brick

14 wall.

15 CW: Okay? hh How can I help then.

16 C: $\quad{ }^{\circ}$ Well ${ }^{\circ}$ basically what it is uhm: a-bou:t I-I suffer

17 from uh- a disease

(14) (MP01.Phone-1KK_07)

1 CW: Michael $\uparrow$ Johnson's office, $\uparrow \underline{\text { Ann }}$ speaking, how can

2 I help you.

3 C: erm Hiya. Sorry I don't know:, like quite whoever to

4 speak to or anything, but erm: I'm a resident of

$5 \quad$ Barnslow and I'm- I'm visually impair:ed

(15) (MP01.Phone-1KZ2_01)

1 CW: Jacob Moore's office, $\uparrow$ Gail: speaking, How can I

2 help you. 
3

4 C: $\quad$ Oh hello. $=$.hh uh Is it $\uparrow$ possible to speak to uh

5

6

7

8

9

(0.4) Jacob $\downarrow$ Moore please. $=$

CW: $\quad=. \mathrm{HH}$ No::. $=$ I'm sorry I'm afraid he's in London at the moment, But I'm his caseworker can I help you:, (0.3)

C: Oh. Well, Uhm It's about er

In each of the extracts above, the constituents display uncertainty about how the constituency office service works. In Extracts (13) and (14), the constituents explicitly index that they are uncertain who to speak to (lines 12-14, and 3 and 4, respectively). In Extract (15), the constituent displays an expectation that the MP would either have answered the phone or be present, via being informed ("Oh hello", line 4) on speaking to the caseworker, and asking to speak to the MP. Familiar constituents, in contrast, ask to speak to the caseworker they know, displaying familiarity with the office procedure. One does not typically call up a doctor and expect them to answer the phone; we have competence in our local office via having dealt with them before. Unlike Stokoe's (2013) mediation calls, however, only one explicit explanation of the services available occurred, and at the direct request of a constituent:

(16) (MP01.Phone-2AH_01)

1 CW: .hhh Good morning Michael Johnson's office

2 (.)

3 C: $\quad$.hh Hi there y'all right, uhhm (.) I'm sort'uv um

4 calling to see if it's the best number to speak to uhm::

((170 lines, describing problem, arranging meeting))

175 C: $\quad$ Okay. Awesome. = ER:M so \#er-e-ih-er\# JUSt so

176 I know: what roughly what you guys do, [I mean

177 CW: [Mm,

178 C: I've (0.2) You know I 'preciate, A lot [a pe]ople

179 CW: [Yea.]

180 C: = keep saying, con [tact] you,\# wha- wha- What =

181 CW: [Yea.]

182 C: = exact(.)ly CAN you do, = or what are the options or

183 [what's,

184 CW: [Erahhh\# WELl- my- my role is a CAseworker, (.) erm

185 So there's two caseworkers here. So we deal with all

186 sorts of ${ }^{\circ} f^{\circ}$ problems issues that (.) Michael: gets his

187 way, .hhh er::m [So:] a- 
188 C: [Mm, ]

189 CW: but we- we quite Often: coun- erm contact the

190 council, (.) about various (.) things like this, = So,

191 so we can, (0.2) we can write letter:s (.) Do that

192 sort of thing:, so, .hh It just depends what the

193 issue is really,

$194 \quad(0.9)$

195 C: Right,

C expresses an opening similar to previous extracts, explicitly indexing his uncertainty as to whether this is "the best number to speak to" (line 4). After arranging an appointment, he asks "roughly what you guys do" (line 176), and "What exact(.)ly CAN you do" (lines 180-182), explicitly requesting information on what service the office provides. CW's description of what they "can do" is delayed, and does not specify abilities or services. CW returns to a case-specific focus in saying what they "often" do (line 189) in relation to C's particular problem. C does not treat this as a complete answer, eventually giving a delayed, neutral receipt (line 195). They subsequently delay further explanation to the meeting (the meeting is recorded; further explanation does not take place).

Extract (16) shows a deviant case; in most calls, any uncertainty indexed is not a barrier to service in the same way as Stokoe's (2013) mediation calls. Constituents and the caseworkers proceed with providing service even when uncertainty is described - only in Extract (16) is service ever delayed by a request for explanation, and even there the explanation is minimal and abandoned. Specific descriptions of "what we do" are only given when directly asked (this extract is the only interaction in the corpus where such a description is requested or given). Neither constituents nor caseworkers typically make relevant what the office "can" do - and above, where such a question is asked, it is answered by focusing on what they "often" do. As CW says above, "It just depends on what the issue is really," (lines 192 and 193); the office finds service to provide for the cases that arrive. Thus, the office in this data corpus solves the question of what an MP "does" via what happens in each case, rather than defining a role.

\section{Discussion}

In this paper, we have begun to shed light on an important, yet unstudied, aspect of an MP's occupation: the interactions that constitute constituency casework and service provision for constituents. In particular, we have demonstrated the 
practices used by constituents in securing assistance services at a constituency office. We have shown that constituents typically begin encounters with bids to tell narratives. After being granted extended turn space, constituents achieve recruitment through narrative descriptions of their difficulties. These descriptions manage contingencies such as the legitimacy and reasonableness of the difficulty, while constructing the entitlement of the constituent to aid.

Constituents also show some orientations to uncertainty about the constituency office institution, as seen in actions that demonstrate a lack of familiarity with the way the institution runs, explicit statements of uncertainty, and one instance of directly asking for information on what the office "does". The use of initial bids of turn space, narrative descriptions, and the continued descriptions following an offer, may also manage the issue of the "unknown" institution. Many constituents in the data have faced rejection after rejection from other institutions, who have said that their case is not actionable. By the time they reach the constituency office, it is unclear if their case is actionable at all, let alone by constituency staff. The descriptions provide constituents with ample interactional space to outline the complex, often lengthy histories of their problems (from calls, at least 12 cases had been facing difficulty for over a year, including two for up to ten years, and another 20 had been facing their problem for at least three months). The narrative descriptions also may circumvent specific or direct requesting, allowing the office to pick up and offer on what is actionable, while also accomplishing the other elements of legitimacy and relevance. Future work with this material can systematically identify if and how constituents leave space, and whether and how staff use such a resource. This will also expand previous work showing how the staff design their offers in a way that is sensitive to what is offer-able (Hofstetter and Stokoe 2015). As with extended request sequences in service environments, "[w]hat the request ends up to be is thus a joint construction between the parties” (Lee 2009: 1255).

There are many analogies between the MP “surgery” and a doctor's surgery, or doctor-patient interactions. Doctorability has been mentioned above, but we also note "diagnostic" questions (Stivers and Heritage 2001), narratives of discovery (Halkowski 2006) as compared to narratives of history, and resistance to proposed actions (Gill et al. 2010; Stivers 2006). Future work should attempt a systematic comparison, situating the constituency office among other institutions that have been analyzed interactionally. However, there are risks to doing this when the data set for the constituency office is limited to only one location; the comparable data for other services is broader and shows a larger set of different participants enacting a theoretically similar role. The key question is whether participants orient to the settings as different, and in what ways. 
Finally, it is worth noting that it may be useful for the MP to permit and even encourage such extended narrative descriptions. Although the MP and caseworkers in the study expressed interest in being more time effective, they also benefit from having opportunities to affiliate with the constituents. If one of the aims of the constituency service environment is to connect with local citizens, the MP and caseworkers require interactional space to create affiliative moments. Hearing the constituents' problems in detail is not only necessary in order to provide service, it may also be necessary if the constituent is to feel taken care of. The constituency office is not a place where a service is merely "transacted." The service provision itself serves the higher purpose of meeting and connecting with the Member of Parliament.

\section{Appendix: Jefferson transcription key}

$\mathrm{t}[$ alk [Yeah, $\uparrow \downarrow$ Underlining CAPITALS ${ }^{\circ}$ I know ${ }^{\circ}$ \#I know\# (0.4)

(.) ((stoccato)) wa::nted hhh

.hhh

Yeh, yeah? Yeah.

bu- u$>$ he said < $<$ he said > solid. = $=$ We had sto(h)p
Square brackets indicate start and end of overlapping speech.

Marked pitch movement, beyond normal rhythms of speech. Indicates emphasis; more underlining is more emphasis. Indicates louder volume than surrounding speech. Indicates quieter speech. Indicates creaky voice. Numbers in round brackets measure pauses in seconds. A micropause, hearable but too short to measure. Additional comments from the transcriber. Elongation of prior sound; more colons shows more elongation. Out breath, proportionally as for colons. In breath proportionally as for colons. Comma: weak rising intonation, as when delivering a list. Question mark: strong rise in intonation, irrespective of grammar. Full stop: marks falling, stopping intonation irrespective of grammar.

Cut-off of the preceding sound. Faster than surrounding talk. Reverse indicates slower than surrounding talk. Indicates "latching" of successive talk, no silence between talk. Shows laughter particles. 


\section{References}

Baker, Carolyn, Michael Emmison \& Alan Firth. 2001. Discovering order in opening sequences: Calls to a software helpline. In A.W. McHoul \& M. Rapley (eds.), How to analyse talk in institutional settings: $A$ casebook of methods, 41-56. London: Continuum International.

Butler, Patrick \& Neil Collins. 2001. Payment on delivery: Recognising constituency service as political marketing. European Journal of Marketing 35(9/10). 1026-1037.

Curl, Traci \& Paul Drew. 2008. Contingency and action: A comparison of two forms of requesting. Research on Language and Social Interaction 41(2). 129-153.

Drew, Paul \& Elizabeth Couper-Kuhlen. 2014. Requesting - From speech act to recruitment. In Paul Drew \& Elizabeth Couper-Kuhlen (eds.), Requesting in social interaction, 1-34. Amsterdam: John Benjamins.

Drew, Paul. 1984. Speakers' reportings in invitation sequences. In J.M. Atkinson \& J. Heritage (eds.), Structures of social action: Studies in conversation analysis, 129-151. Cambridge: Cambridge University Press.

Edwards, Derek \& Elizabeth Stokoe. 2007. Self-help in calls for help with problem neighbors. Research on Language and Social Interaction 40(1). 9-32.

Gay, Oonagh. 2005. MPs go back to their constituencies. The Political Quarterly 76(1). 57-66.

Gill, Virginia T., Anita Pomerantz \& Paul Denvir. 2001. Pre-emptive resistance: Patients' participation in diagnostic sense-making activities. Sociology of Health \& Illness 32(1). $1-20$.

Halkowski, Timothy. 2006. Realizing the illness: Patients' narratives of symptom discovery. In John Heritage \& Douglas Maynard (eds.), Communication in Medical Care: Interaction between Primary Care Physicians and Patients, 86-114. Cambridge: Cambridge University Press.

Heitshusen, Valerie, Garry Young \& David M. Wood. 2005. Electoral context and MP constituency focus in Australia, Canada, Ireland, New Zealand and the United Kingdom. American Journal of Political Science 49(1). 32-45.

Heritage, John \& Steven Clayman. 2010. Talk in action: Interactions, identities, and institutions. Oxford: Wiley-Blackwell.

Heritage, John \& Douglas Maynard (eds.). 2006. Communication in medical care: Interaction between primary care physicians and patients. Cambridge: Cambridge University Press.

Heritage, John \& Jeffrey Robinson. 2006. Accounting for the visit: Giving reasons for seeking medical care. In John Heritage \& Douglas W. Maynard (eds.), Communication in medical care: Interaction between primary care physicians and patients, 48-85. Cambridge: Cambridge University Press.

Hofstetter, Emily. 2016. Citizens getting help: Interactions at the constituency office. Doctoral dissertation. Loughborough: Loughborough University.

Hofstetter, Emily \& Elizabeth Stokoe. 2015. Offers of assistance in politician-constituent interaction. Discourse Studies 17(6). 724-751.

House of Commons. 2013. You and Your MP: Brief guide. London: Author. Retrieved from: http://www.parliament.uk/documents/commons-information-office/Brief-Guides/Youand-Your-MP.pdf (accessed 20 October 2013).

House of Commons Modernisation Committee. 2007. Revitalising the chamber: The role of the back bench Member. First Report of Session 2006-07, 13 June. London: House of Commons. 
Jefferson, Gail. 2004. Glossary of transcript symbols with an introduction. In Gene H. Lerner (ed.), Conversation Analysis: Studies from the first generation, 13-23. Philadelphia: John Benjamins.

Kendrick, Kobin H. \& Paul Drew. 2016. Recruitment: Offers, requests, and the organization of assistance in interaction. Research on Language and Social Interaction 49(1). 1-19.

Korris, Matt. 2011. A year in the life: From member of public to Member of Parliament. London: Hansard Society.

Le Lidec, Patrick. 2009. French deputies, their assistants and the uses of staff appropriations: A sociology of political work. Sociologie du travail 518. e117-e135.

Lee, Seung-Hee. 2009. Extended requesting: Interaction and collaboration in the production and specification of requests. Journal of Pragmatics 41(6). 1248-1271.

Loat, Alison \& Michael MacMillan. 2014. Tragedy in the Commons: Former Members of Parliament speak out about Canada's failing democracy. Toronto: Random House Canada.

Pomerantz, Anita. 1984. Agreeing and disagreeing with assessments: Some features of preferred/dispreferred turn shapes. In J. Maxwell Atkinson \& John Heritage (eds.), Structures of social action: Studies in conversation analysis, 57-101. Cambridge: Cambridge University Press.

Pomerantz, Anita. 1986. Extreme case formulations: A way of legitimizing claims. Human Studies 9(2-3). 219-229.

Potter, Jonathan and Alexa Hepburn. 2003. "I'm a bit concerned"-Early actions and psychological constructions in a child protection helpline. Research on Language and Social Interaction 36. 197-240.

Rawlings, Richard. 1990a. The MP's complaints service. The Modern Law Review 53(1). 22-42.

Rawlings, Richard. 1990b. The MP's complaints service. The Modern Law Review 53(2). 149-169.

Raymond, Geoffrey. 2003. Grammar and social organization: Yes/no type interrogatives and the structure of responding. American Sociological Review 68. 939-967.

Schegloff, Emanuel A. \& Gene H. Lerner. 2009. Beginning to respond: Well-prefaced responses to Wh-questions. Research on Language and Social Interaction 42(2). 91-115.

Sidnell, Jack. 2013. Basic Conversation Analytic Methods. In Jack Sidnell \& Tanya Stivers (eds.), The handbook of conversation analysis, 77-99. United Kingdom: Wiley-Blackwell.

Siefken, Sven T. 2014. The case against (or for?) casework: German MPs' service responsiveness in their district work with citizens. Presented at the ECPR General Conference. Glasgow, September 3-6 2014.

Sikveland, Rein, Elizabeth Stokoe \& Jon Symonds. 2016. Patient burden during appointment-making phone calls to GP practices. Patient Education and Counseling 99(8). 1310-1318.

Sterie, Anca. 2015. Recalling the doctor to action: Two requesting formats employed by a nurse for making relevant the doctor's intervention. Novitas-ROYAL (Research on Youth and Language) 9(2). 118-137.

Stivers, Tanya. 2006. Treatment decisions: Negotiations between doctors and patients in acute care encounters. In John Heritage \& Douglas Maynard (eds.), Communication in Medical Care: Interaction between Primary Care Physicians and Patients, 279-312. Cambridge: Cambridge University Press.

Stivers, Tanya. 2011. Socializing children into the patient role. In Alessandro Duranti, Elinor Ochs \& Bambi Schieffelin (eds.), Handbook of Language Socialization, 247-267. Malden: Wiley-Blackwell. 
Stivers, Tanya \& John Heritage. 2001. Breaking the sequential mold: Answering 'more than the question' during comprehensive history taking. Text 21(1/2). 151-185.

Stokoe, Elizabeth. 2013. Overcoming barriers to mediation in intake calls to services: Researchbased strategies for mediators. Negotiation Journal 29(3). 289-314.

Stokoe, Elizabeth \& Alexa Hepburn. 2005. 'You can hear a lot through the walls': Noise formulations in neighbour complaints. Discourse \& Society 16(5). 647-673.

Vivyan, Nick \& Markus Wagner. 2015. What do voters want from their local MP?. The Political Quarterly 86(1). 33-40.

Whalen, Marilyn \& Don Zimmerman. 1990. Describing trouble: Practical epistemology in citizen calls to the police. Language in Society 19. 465-492.

Zimmerman, Don H. 1992. The interactional organization of calls for emergency assistance. In Paul Drew \& John Heritage (eds.), Talk at work: Interaction in institutional settings, 418-469. New York: Cambridge University Press.

\section{Bionotes}

\section{Emily Hofstetter}

Emily Hofstetter is University Teacher in the Department of Social Sciences at Loughborough University, UK, and Research Associate at University College London in Neonatology. She recently completed her doctoral thesis on how Members of Parliament interact with constituents at MP "surgeries" in the United Kingdom. Her research interests are in conversation analysis across both institutional and mundane settings.

\section{Elizabeth Stokoe}

Elizabeth Stokoe is Professor of Social Interaction in the Department of Social Sciences at Loughborough University, UK. Her current research interests are in conversation analysis, membership categorization, and social interaction in various ordinary and institutional settings, including neighbor mediation, police interrogation, role-play and simulated interaction. She is the co-author of Discourse and Identity (with Bethan Benwell, Edinburgh University Press, 2006) and co-editor of Conversation and Gender (with Susan Speer, Cambridge University Press, 2011). 